\title{
High-temperature multilevel sterilization of canned goods with heat recovery and its constructive and technological support
}

\author{
Mafiiat Rakhmanova ${ }^{1}$, Amiiat Demirova ${ }^{1,2}$, Magomed Akhmedov ${ }^{1,2, *}$, Faina Azimova ${ }^{1}$, Irada Gadzhibekova $^{1,2}$, and Zaurbek \\ Abdulkhalikov $^{1}$ \\ ${ }^{1}$ FSBEO HE Dagestan State Technical University, 367015 Makhachkala, Russia \\ ${ }^{2}$ SEI HPE Dagestan State University of National Economy, 367008 Makhachkala, Russia
}

\begin{abstract}
New technical solutions improving the process of thermal sterilization of canned products through the use of multilevel high-temperature modes and heat recovery have been considered and proposed. The essence of the developed method lies in the fact that the heat released by cooling cans with the product that has undergone thermal sterilization is used to heat other cans with the product queued for sterilization. In this mode of heat treatment, except in the last stage, the heat emitted by cooled cans that have already undergone heat treatment is used to heat up the canned food. Hence, the use of the principle of heat recovery by cooling canned products in the baths where others are simultaneously heated provides a significant saving of heat energy and water. Depending on the temperature parameters at different stages of the heat treatment, the heat recovery rate can reach up to $90 \%$. The method also provides savings on cooling water. For the practical implementation of the developed method, the design of the device for multilevel high-temperature thermal sterilization of canned food with heat recovery has been developed. On the basis of experimental studies, new, multilevel high-temperature modes of apple compote sterilization have been developed.
\end{abstract}

\section{Introduction}

The noncompetitiveness of agroindustrial complex (AIC) processing enterprises, including those producing canned food, is largely based on the inefficiency of energy consumption. Their progressive development is impossible without the introduction of energy-efficient and high-tech production processes and equipment. Primarily, the solution to this problem lies in the development of energy-saving technologies and technologically cost-effective processes and equipment.

AIC enterprises processing raw materials are now searching for energy-saving solutions and technologies that can provide a quick and tangible effect, as reducing energy costs is an effective mechanism for improving the competitiveness of products.

The issues of energy efficiency are now being addressed by the Russian state authorities, which is reflected in the order of the Russian Government of November 13, 2009 No.1715-R "Russia's Energy Strategy for the period up to 2030."

The main, mandatory and final stage, and also the most energy-intensive, in the technological cycle of processing agricultural raw materials into canned foods is the process of sterilization [1-6, 9-11]. This process is used in the production of all long-term storage products in hermetically sealed containers.

There are a large number of methods and equipment for thermal sterilization, which differ in their efficiency, energy costs and applicability for sterilization of canned products of different types [4-6].

Thermal evaluation of the technological cycle of canned food production shows that the most energy intensive process in it is the process of sterilization, and the development of new energy-saving methods and devices for its realization is a pressing problem of food technology. Intensification and increasing the efficiency of sterilization equipment while ensuring high quality of canned products are the main goals set by developers during modernization of traditional and development of new methods and devices for thermal sterilization. Which is why the research of new methods and equipment for efficient thermal sterilization is a very topical problem of practical interest to the AIC enterprises.

\section{Goals and objectives}

The goal of the research is to develop a resource-saving method, mode of its implementation, and the design of an open-type equipment for high-temperature multilevel sterilization of canned food using liquid hightemperature heat carriers and heat recovery.

\footnotetext{
Corresponding author: $\underline{\text { akhmag49@mail.ru }}$
} 


\section{Research objects and methods}

As the object of our research, we chose traditional and high-temperature multi-level sterilization mode of apple compote using the principle of heat recovery in opentype devices. Additionally, we set to propose a design of the equipment for its realization.

During the research, we have experimentally studied compote warming dynamics and developed new multilevel high-temperature sterilization modes. These studies were carried out at an experimental stand facilitating thermal treatment of canned products by rotating glass jars with the product.

The temperature of the product in the wall and central areas of the glass jars was measured using a $\mathrm{Cr}$ $\mathrm{Ni}$ and $\mathrm{Cu}-\mathrm{Ni}$ thermocouple connected to the potentiometer KSP 4.

\section{Results and discussion}

The research was conducted at the laboratory base of the Dagestan State Technical University.

The final stage of thermal sterilization of canned products in hermetically sealed containers is the cooling process, which is carried out in a variety of ways. All traditional methods are based on the fact that the heat removed from the cans being cooled, together with the cooling water or air, is released into the environment. And the development of methods and equipment allowing to reuse the heat removed from the cans being cooled for the cans queued for heating is an important scientific and technical solution to the task of implementation of resource-saving technologies.

We have developed a new method of multilevel thermal sterilization of canned food using the principle of heat recovery, the essence of which is that the heat emitted by cooling some cans is used to heat the others.

The use of the principle of heat recovery by cooling canned products in the same baths where others are simultaneously heated provides a significant saving of heat energy and water. In this implementation of heat treatment, except in the last stage, the heat emitted by cooled cans that have already undergone heat treatment is used to heat up the canned food.

Depending on the temperature parameters at different stages of the heat treatment, the recovery rate can reach up to $90 \%$. The method also provides savings on cooling water. For the practical implementation of the developed method, an open-type device for multilevel hightemperature sterilization of canned products with reuse of thermal energy has been designed, the scheme of which is presented in Figure 1 [10].

The design of the device includes a frame 1, with five baths containing heat carrier at different temperature levels installed on it, the walls of which are covered with insulation material separated from each other by insulating partitions. The first bath is the final cooling stage of the glass jars with the product, and the fifth bath, which uses a high-temperature liquid heat carrier, $40 \%$ solution of dimethyl sulfoxide, is the final stage of heating. In the remaining three baths, the second, third and fourth, simultaneous processes are carried out: the glass jars with the product coming on the top row are heated up by the heat emitted by cooling the glass cans with the product travelling on the bottom row, in the corresponding baths. Two parallel Gall's chains 6 driven by the sprockets 3 are used as the transportation organ of the device. Glass jars with the product after capping arrive in the loading node, where they are loaded into the carriers attached to the shafts 14 , fixed in the roller bearings 16 , installed on the corners 17 , welded to the inner wall of the body of the device at a certain range. The movement of the transportation organ is facilitated

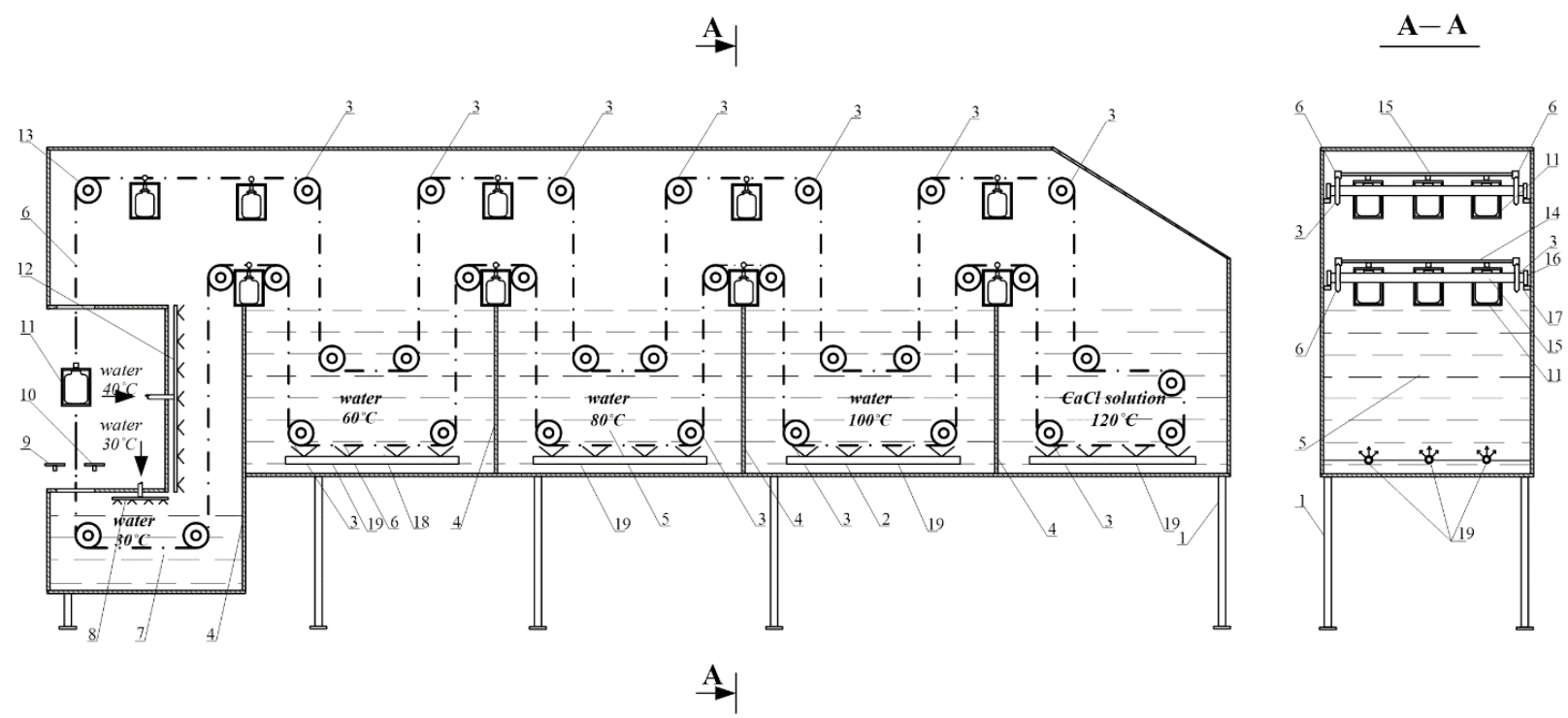

Fig. 1. Device for multilevel high-temperature thermal sterilization of fruit and vegetable canned goods in liquid hightemperature heat carriers using secondary heat resources. It contains a frame 1 , heating elements 2 , sprockets 3 , separators 4 , baths for heating and cooling 5 and 18, Gall's chain 6 , bath for cooling 7; showers 8 and 12, inbound transporter for cans 9 , outbound transporter for cans 10 , can carriers 11 , a drive sprocket 13, shafts 14, guides 15, bearings 16, and corners 17 . 
Table 1. Multilevel high-temperature sterilization modes.

\begin{tabular}{|c|c|c|c|}
\hline $\begin{array}{c}\text { Canned } \\
\text { product name }\end{array}$ & $\begin{array}{c}\text { Volume of jars, } \\
\text { I }\end{array}$ & $\begin{array}{c}\text { Duration of traditional modes, } \\
\text { min }\end{array}$ & $\begin{array}{c}\text { Multilevel thermal sterilization modes } \\
\text { with heat recovery }\end{array}$ \\
\hline \multirow{2}{*}{ Apple compote } & 1.0 & 85 & $\left(\frac{6}{60} \cdot \frac{6}{80} \cdot \frac{6}{100} \cdot \frac{6}{110}\right) \cdot\left(\frac{6}{80} \cdot \frac{6}{60} \cdot \frac{6}{40}\right) \cdot 0.2$ \\
\cline { 2 - 4 } & 0.5 & 65 & $\left(\frac{4}{60} \cdot \frac{4}{80} \cdot \frac{4}{100} \cdot \frac{4}{110}\right) \cdot\left(\frac{4}{80} \cdot \frac{4}{60} \cdot \frac{4}{40}\right) \cdot 0.15$ \\
\hline
\end{tabular}

by the driver through the driving sprocket 13 .

The device operates in the following manner. Gall's chains 6 together with fixed carriers for glass jars make intermittent progressive movement, moving from bath to bath. They start with the second one, alongside sterilized jars secured in carriers, then proceed into the third, fourth and fifth baths on the upper branch of the transporting organ and further onto the lower branch returning to the fourth, third, second and first for final cooling. At the same time, the supply of cans into the carriers 11 is carried out during the stops of the transporting organ. The jars installed into carriers ensuring their mechanical hermitization sequentially pass the second, third, fourth and fifth baths for successive heating. In the second, third, and fourth baths, the jars supplied on the top branch are heated through the cooling of glass jars with the product supplied on the lower branch of the transporter into these very baths. The fifth bath with high-temperature heat carrier is only used for heating, and in the first bath with water at $40{ }^{\circ} \mathrm{C}$, the final cooling is carried out. The heat carrier temperatures in the baths are automatically supported at, respectively, $40^{\circ} \mathrm{C}, 60^{\circ} \mathrm{C}, 80^{\circ} \mathrm{C}, 100{ }^{\circ} \mathrm{C}$, and $120^{\circ} \mathrm{C}$. The proposed design solution, with the movement of cooled cans in the bottom row and heated ones in the upper, also contributes to the natural circulation of the heat carrier in the baths.

The heat consumption in the unit takes place only in the fifth bath for heating canned food from $92-95^{\circ} \mathrm{C}$ to $100{ }^{\circ} \mathrm{C}$ (for acidic canned foods, sterilized at $100{ }^{\circ} \mathrm{C}$ ) and up to $115-118^{\circ} \mathrm{C}$ (for non-acidic canned food, sterilized at temperatures of $116-120^{\circ} \mathrm{C}$ ), as well as to compensate for environmental losses, and water is consumed only in the first bath for cooling canned food from $60-65^{\circ} \mathrm{C}$ to $40{ }^{\circ} \mathrm{C}$.

The savings in heat energy and water compared to the periodic-action devices used in the industry (autoclaves) are over $90 \%$.

The increase in the recovery rate can be achieved by changing the temperature parameters of the heating of canned food in the penultimate bath for heating. The higher this temperature, the greater the recovery factor. When the method is implemented in practice, the coefficient reaches up to 0.90 .

On the basis of experimental studies on warming dynamics of apple compote in different containers, new multilevel high-temperature rotational sterilization modes have been developed [11-18] (Table1).

The formulas of multilevel sterilization modes in the numerator indicate the duration of the heat treatment in minutes, and in the denominator they contain the temperature levels of the coolant at each stage of the thermal treatment in ${ }^{\circ} \mathrm{C}$ and the frequency of rotation of the glass cans in $\mathrm{s}^{-1}$.

\section{Conclusion}

A new way of multilevel high-temperature thermal sterilization of canned food with heat recovery and rotation of glassware has been developed. Hightemperature multilevel thermal sterilization modes for apple compote in various containers, the duration of which is more than $50 \%$ less than that of the modes of traditional technology have been established. Moreover, it provides for saving in excess of $90 \%$ of heat energy due to its reuse.

The technical solutions presented can be recommended for use in AIC enterprises as providing high quality and safety of products and resource conservation.

\section{References}

1. M.E. Akhmedov, A.F. Demirova, G.I. Kasyanov, A.M. Darbisheva, T.N. Daudova, L.A. Daudova, Russian Agricultural Sciences, 42 (1), 113-116 (2016)

2. G. Kasyanov, T. Davydenko, Food Science and Technology, 11 (1), 75-78 (2017)

3. K. Sakibaev, L. Pylypenko, T. Nikitchina, G. Kasyanov, Food Science and Technology, 13 (2), 128-135 (2019)

4. A.F. Demirova, M.E. Akhmedov, M.M. Alibekova, T.N. Daudova, M.M. Omarov, Z.A. Abdulkhalikov, Russian Agricultural Science, 4, 61-64 (2018)

5. M.D. Mukailov, N.A. Ulchibekova, T.A. Isrigova, M.E. Akhmedov, U.A. Selimova, International Journal of Advanced Science and Technology, 29 (9s), 1167-1172 (2020)

6. M. Akhmedov, A. Demirova, V. Piniaskin, R.A. Rakhmanova, E3S Web of Conferences, 161 (1), 01056 (2020)

7. M. Akhmedov, A. Demirova, Z. Abdulkhalikov, T. Daudova, L. Daudova, E3S Web of Conferences, 161 (2020)

8. V. Derevenko, G. Kasyanov, L. Pylypenko, Food Science and Technology, 12 (2), 39-45 (2018)

9. M. Aider, E. Olkhovatov, L. Pylypenko, T. Nikitchina, G. Kasyanov, Food Scienceand Technology, 12 (4), 63-71 (2018) 
10. T.A. Ismayilov, A.F. Demirova, M.E. Akhmedov, M.M. Akhmedova, A device for high-temperature thermal sterilization of canned products (Pat. RF no. 2604919, bull. no. 35, 20.12.2016)

11. Collection of technological instructions for the production of canned goods, Moscow, 2, 355 (1977)

12. B.L. Flaumenbaum, S.S. Tanchev, M.A. Grishin, Basics of food sterilization (Agropromizdat, Moscow, 1986, 264)

13. V.P. Babarin, Sterilization of canned food (GIORD, St. Petersburg, 2006, 312)

14. G.I. Kasyanov, A.F. Demirova, M.E. Akhmedov, Reports of the Russian Academy of Agricultural Sciences, 6, 57-59 (2014)

15. G.I. Kasyanov, Bulletin of Universities, Food Technology, 1, 35-38 (2014)

16. O.R. Panina, G.I. Kasyanov, S.V. Rohman, Bulletin of Universities, Food Technology, 1, 122-124 (2014)

17. M.E. Akhmedov, N.G. Zagirov, A.F. Demirov, M.M. Akhmedova, R.A. Rakhmanova, Equipment for heating fruits and vegetables in jars (Pat. RF no. 2666371, 07.09.2018)

18. Guide on the development of sterilization and pasteurization regimes for canned products (GNU VNIICOP, 2011) 